\title{
A relação entre a carreira do magistério superior, suporte familiar e estresse ocupacional dos docentes da Universidade Federal de Viçosa-MG
}

The relationship between career top magisterium, family support and occupational stress of teachers in Federal University of Viçosa-MG

\author{
Michelle BARBosa SOARES* \\ SiMONE CALDAS TAVARES MAFRA** \\ EVANDRO RODRIGUES DE FARIA***
}

\begin{abstract}
8003
RESUMO - A família compõe uma função importante na vida emocional das pessoas, pois é a base da constituição de um modelo relacional, desde as laborais, de amizade e de parentesco. 0 suporte familiar é uma manifestação de atenção, carinho e diálogo existente entre os integrantes da família. Dessa forma, esse estudo objetivou verificar a relação entre o suporte familiar e a carreira docente e compreender suas interferências no estresse ocupacional. 0 estudo foi realizado na cidade de Viçosa-MG, tendo como unidade de pesquisa a Universidade Federal de Viçosa, (UFV) Campus Viçosa. Os resultados revelaram que o suporte familiar está presente no cotidiano dos docentes da UFV, porém o excesso de trabalho, de produtividade, a vaidade e até mesmo o perfeccionismo geram uma sobrecarga aos docentes universitários. Desse modo, a sobrecarga prejudica as relações familiares, diminui os momentos de lazer, causa sentimento de culpa, angústia, tristeza e de abandono à família, afetando, assim, o convívio familiar.

Palavras-chave - Suporte familiar. Universidade pública. Trabalho.

ABSTRACT - Family plays an important role in the emotional life of people as it is the basis for the establishment of a labor relations' model, friendship and kinship too. Family support is a manifestation of attention, care and dialog between family members. Thus, this study aimed to investigate the relationship between family support and teaching career, understand their influence on occupational stress. The study was conducted in Viçosa-MG, and the research unit was Universidad Federal de Viçosa (UFV), Viçosa campus. The results revealed that family support is present in the daily lives of the UFV professors. But overwork, productivity, vanity and even perfectionism generates a burden on them, this overhead affects family relationships, reduces leisure time, cause feelings of guilt, anxiety, sadness and sense of abandonment to family, affecting family life too.
\end{abstract}

Keywords - Family support. Public university. Work.

\footnotetext{
* Mestre e doutoranda pela Universidade Federal de São Carlos (UFSCAR). Professora na Faculdade de Ciências Biológicas e da Saúde (FACISA), Viçosa/MG - Brasil. CV: http://lattes.cnpq.br/5516759349617622. E-mail: msmichellesoares@yahoo.com.br.

${ }^{* *}$ Doutora pela Universidade Federal de Santa Catarina (UFSC). Professora na Universidade Federal de Viçosa (UFV), Viçosa/MG Brasil. CV: http://lattes.cnpq.br/7276765928582051. E-mail: sctmafra@ufv.br.

*** Doutor pela Universidade Federal de Minas Gerais (UFMG). Professor na Universidade Federal de Viçosa (UFV), Viçosa/MG Brasil. CV: http://lattes.cnpq.br/0424478495500101. E-mail: evandrozd@hotmail.com. Submetido em: agosto/2016. Aprovado em: setembro/2017.
} 
família compõe uma função importante na vida emocional dos indivíduos, pois é a base da constituição de um modelo relacional que proporciona a concepção de outras relações, desde as laborais, de amizade, de parentesco, até a construção de uma nova família. Através de normas e funções seus membros as assimilam, por oposição ou similaridade, se identificam com seu grupo familiar. Essas identificações não interferem apenas na construção cognitiva e de personalidade, mas igualmente reproduzem situações de interação, jogos relacionais e formas de manifestar afetos e emoções (CEBERIO, 2006). É por meio da família que o indivíduo se constrói psicologicamente, passando gradualmente de uma conjuntura indiferenciada, no qual ele ainda não se vê como ser único, dependendo da família, para um estado de individualização, no qual ele torna-se independente, um indivíduo completo para viver em sociedade (ANDOLFI et al., 1994).

Conforme Campos (2004), a família também exerce funções como proteção, afeição e formação social, e o desenvolvimento da confiança em um membro da família acontece a partir da autonomia e da proteção que lhe é oferecida de forma equilibrada pelos seus familiares. A consequência da efetivação dessas funções familiares ocorre quando os membros da família a compreendem como predominantemente afetuosa, coesa, com boa comunicação e regras flexíveis, desde que os limites e fronteiras estejam claros, provendo recursos necessários ao crescimento individual e apoio diante de dificuldades ou doenças intercorrentes.

Mediante todas as funções referentes à família surge o conceito de suporte familiar. Segundo Baptista e Oliveira (2004), o suporte familiar é uma manifestação de atenção, carinho, diálogo, liberdade, proximidade afetiva, autonomia e independência existente entre os integrantes da família (características psicológicas), dessa forma diferencia-se do conceito de estrutura familiar, que se refere mais especificamente ao número de pessoas pertencentes a uma família, sua disposição e composição (características físicas). O suporte familiar ocorre na proporção em que o receptor percebe esse apoio como satisfatório, sentindo-se amado, valorizado, compreendido, reconhecido, acolhido, protegido e cuidado e, ainda, compartilhando de uma rede de recursos e informações. Assim, quando o indivíduo sente esse suporte encontra forças para enfrentar situações adversas, essa sensação ocasiona consequências positivas para seu bem-estar, como redução do estresse, aumento da autoestima e do bem-estar psicológico (CAMPOS, 2004).

Existe uma relação delicada e íntima entre a família e a carreira profissional, sendo as duas consideradas de grande importância para o homem, porém uma pode interferir no papel da outra, ora positivamente, ora negativamente. Dessa forma, nota-se a importância do suporte familiar na vida do docente universitário, baseando-se nos índices de prevalência e incidência de alterações na saúde dos docentes. De acordo com um estudo que abrangeu todo o território nacional, realizado por Codo (1999), $26 \%$ dos professores no Brasil apresentavam um nível de exaustão emocional considerado perigoso à saúde mental dos mesmos. No entanto, não é um privilégio do Brasil. Vários outros estudos internacionais verificaram que as condições adversas da docência escolar são múltiplas e contribuem para altos índices de estresse ocupacional e Burnout (BETORET; ARTIGA, 2010; KERR et al, 2011; KOKKINOS, 2007; MONTGOMERY; RUPP, 2005; YONG; YUE, 2007).

Por isso a importância do suporte familiar na vida do docente. Também em uma outra perspectiva relacionada à carreira docente, pois os professores têm funções que transcendem o ensino e a produção de conhecimentos e são cobrados na produção e publicação técnico-científica, realizam e desenvolvem projetos de pesquisa, ensino e extensão, além das atribuições administrativas, a participação em reuniões, a realização de processos e outras funções burocráticas. Estas exigências decorrentes de sua atuação acadêmica podem influenciar negativamente em seu estilo de vida e, consequentemente, em diferentes aspectos de sua qualidade de vida.

Mediante o exposto, esse estudo teve como objetivo verificar a relação entre o suporte familiar e a carreira docente, compreender suas interferências no estresse ocupacional e averiguar a percepção dos docentes universitários, lotados no campus Viçosa-MG, sobre a importância do suporte familiar na perspectiva de avaliar a relação com o estresse ocupacional e pessoal. 


\section{A carreira docente}

O surgimento da carreira docente pode ter ocorrido na sociedade greco-romana onde encontra-se vestígios nos escritos antigos da época (SINGER, 1986). Conforme Fernandes (1998), a origem da profissão docente pode ser atribuída, entre outras, à sociedade ateniense. Em Atenas, existia um antagonismo pedagógico que se reflete até os dias atuais, já que havia um debate sobre a opção por um paradigma socrático-platônico ou o paradigma sofista. O primeiro paradigma exigia que o docente fosse um mestre de vida e de pensamento de seus discípulos, e que deveria se dedicar completamente à função sem qualquer tipo de pagamento, apenas pelo amor a mesma (SILVA, 2006). O segundo paradigma considerava que a docência era uma profissão cuidadosa da sua reputação e da ciência professada, a qual poderia inclusive ser discutida em praça pública e com remuneração para tal função. Fernandes (1998) destaca que o primeiro paradigma inerente à docência representa o que era entendido por vocação e o segundo por profissão.

Já na atualidade, a carreira na universidade passa por crises que seguem a lógica da pósmodernidade. Essas crises abrangem três aspectos: a hegemonia, a legitimidade e a instituição (PEREIRA, 2006). A crise da hegemonia ou de identidade questiona sobre a exclusividade dos conhecimentos que a universidade produz e transmite (CASTANHO; CASTANHO, 2004). A crise de legitimidade se distingue como sendo a contradição existente entre a hierarquização e a democratização que atinge o seu papel social. Já a crise institucional decorre da autonomia que é própria da universidade, mas que está atrelada ao discurso da produtividade medida pela avaliação institucional e pelo "ranqueamento" das instituições. Esta crise abala as relações de poder da universidade com a sua estrutura de sustentação, ou seja, os docentes (PEREIRA, 2006).

Esses docentes que atuam nas instituições de ensino superior enfrentam obstáculos para manter seu tripé de atuação (ensino, pesquisa, extensão), que está diretamente relacionada à produção e transferência dos conhecimentos produzidos na academia e repassados ao sistema de produção de bens e serviços (TAFFAREL, 1997; OLIVEIRA, 1997; DARIDO, 1998). Possuem, também, segundo Fernandes (1998), cinco particularidades que diferenciam este nível de atuação dos demais níveis de educação, que são: a formação intelectual longa, a aquisição de uma competência técnica e princípio de especialização, a perspectiva da oferta de um serviço relevante para o conjunto da coletividade, o controle pelos pares das formas de competência, o desenvolvimento de uma autonomia profissional.

Debatendo os dilemas atuais no desempenho docente universitária, lanni (1986, p. 74) cita que: "[...] nessa nova organização, o capital industrial, o grande capital, tomou conta da sociedade numa escala surpreendente [...] esse predomínio do capital tomou conta do Estado e influenciou amplamente a cultura lato sensu e a própria universidade".

Deste modo, é possível inferir que a influência do modelo produtivo sobre a universidade é um aspecto de significativa relevância para o estudo do ensino universitário. Essa lógica de mercado pode não proporcionar um professor crítico, culto e comprometido com a educação, mas um profissional com formação abreviada para atender a demanda de mercado, além da necessidade da submissão às regras de mercado visando à própria sobrevivência econômica (SILVA, 2006).

Além disso, Perez (1992) identifica fatores relacionados ao trabalho docente tais como a precariedade dos recursos didáticos, as normas e procedimentos administrativos inadequados, as excessivas funções burocráticas atribuídas ao docente, as interrupções durante as aulas, as condições físicas deficitárias das instalações e a remuneração insuficiente que podem levar o docente a apresentar sintomas do estresse. Compreende-se, ainda, a prevalência de situações estressantes que prejudicam a saúde dos docentes e que interferem nos seus desempenhos pessoal e profissional, com manifestação de sintomas associados ao estresse como agitação e apatia (CONTAIFER et al., 2003; SILVA, 2006).

Dessa forma, recomenda-se que o homem recupere o seu papel social produtivo, deixando de ser alienado a toda esta realidade, se conscientizando de sua importância como um ser que precisa de 
motivação, de satisfação plena, de ter autoestima e de ser útil (PEREIRA, 2006). Para isso, é necessário considerar o suporte familiar dos docentes universitários como um conceito amplo que deverá englobar aspectos subjetivos como sentimentos, percepções, bem-estar, grau de pertencimento a família, relacionamentos interpessoais, manifestação de atenção, carinho, diálogo e proximidade afetiva, pois a família poderá ser um alicerce, ajudando o docente a lidar com as situações adversas no seu ambiente de trabalho, caso exista um suporte familiar adequado.

\section{Suporte familiar}

A relação do estresse ocupacional e suas consequências na família é um aspecto importante a se considerar quanto ao cotidiano dos indivíduos (LIPP; MALAGRIS, 2001). Por isso, é necessária maior atenção não só aos efeitos do estresse ocupacional sobre a família, mas também às implicações que uma vida familiar estressante pode ter na criatividade e no trabalho.

Assim, a relação trabalho versus família é uma relação biunívoca onde o trabalho afeta a família e a família afeta o trabalho. Por mais que se diga que os problemas de casa não são ou não devem ser levados para o trabalho, nem sempre isso é possível.

Dessa forma, é necessário identificar os fatores organizacionais propensos a contribuir para o adoecimento da relação familiar, a fim de evitar que o estresse da família retorne de forma direta para o ambiente de trabalho. Por outro lado, é importante identificar fatores familiares que possam interferir também no desempenho ocupacional (LIPP, 2005).

Nesse sentido, o suporte familiar tem potencial para amenizar os efeitos estressores, sendo essencial para melhorar a qualidade de vida do trabalhador. Baptista e Oliveira (2004) entendem suporte familiar como manifestação de atenção, carinho, diálogo, liberdade, proximidade afetiva, autonomia e independência existente entre os integrantes da família (características psicológicas).

A percepção e o recebimento dos suportes sociais, incluindo o familiar, pelas pessoas, são fontes fundamentais na manutenção da saúde mental, no enfrentamento de situações estressantes, na promoção de benefícios nos processos fisiológicos (sistema endócrino, cardiovascular e imunológico) e no alívio dos estresses físico e mental (CAMPOS, 2004).

Algumas características do suporte familiar são objeto de pesquisa. Essas pesquisas contribuíram para desenvolver instrumentos de medida de suporte familiar. Olson et al. (1983), por exemplo, desenvolveram um modelo teórico complexo dos sistemas familiares e discutem neste modelo vários aspectos importantes das relações familiares, tais como: a coesão, a adaptabilidade e a comunicação familiar. Olson et al. $(1983$, p. 77) referem que:

A coesão estaria relacionada aos tipos de vínculos que os membros familiares estabelecem, que incluem a forma de realização dos processos de decisão, o tempo que as pessoas passam juntas, os interesses familiares comuns, os limites, as ligações entre as pessoas e os interesses nas atividades recreativas. A adaptabilidade seria a habilidade de o sistema familiar transformar a estrutura de poder e as regras nos relacionamentos, em resposta a situações geradoras de estresse.

Por conseguinte, a comunicação seria uma dimensão crítica nas famílias, o que proporcionaria, inclusive, a facilitação das características da coesão e adaptabilidade. Ela seria composta pela empatia entre os membros, o ouvir reflexivo e suportivo, além da expressão, compartilhamento afetivo e a sensação de conforto emocional entre os membros familiares.

Dentro da atividade docente, as atividades de final de bimestre ou de ano, onde há um acúmulo de provas e trabalhos para serem corrigidos, por exemplo, têm interferido na dinâmica familiar. Se isso ocorre, parece que o conflito trabalho versus família passa a ser o esperado (VASQUES-MENEZES et al., 2013).

Assim, o suporte familiar torna-se a chave para entender o comportamento dos indivíduos dentro da profissão docente, devido ao fato de esta profissão ter um potencial de interferir nos níveis de estresse do profissional. 


\section{Metodologia}

\section{Caracterização da pesquisa}

A presente pesquisa é do tipo qualitativa, tendo como foco de estudo a verificação do suporte familiar nos docentes da UFV através da análise de conteúdo. $O$ trabalho qualitativo produz conhecimento com problemas reais e condições de soluções, pois deriva do contexto social e busca compreender a subjetividade, as práticas e as experiências dos envolvidos. A ênfase ocorre nos aspectos local, temporal e nos padrões que delimitam a situação, porque procura entender a realidade em seus próprios termos.

\section{Local do estudo}

O estudo foi realizado na cidade de Viçosa-MG, tendo como unidade de pesquisa a UFV campus Viçosa.

A UFV originou-se da Escola Superior de Agricultura e Veterinária (ESAV), fundada em 30 de março em 1922. Hoje, após 93 anos de existência, a instituição possui 45 cursos de graduação que se organizam nos seguintes Centros de Ciências: Ciências Agrárias (CCA), Ciências Biológicas e da Saúde (CCB), Ciências Exatas e Tecnológicas (CCE) e Ciências Humanas, Letras e Artes (CCH). Conta também com um total de 44 cursos de pós-graduação stricto sensu no campus Viçosa. A relevância deste local para o estudo proposto está no fato de ser a UFV referência nacional e internacional no ensino e na pesquisa, e por ser considerada uma das instituições brasileiras com índices mais elevados de qualificação do quadro de pessoal docente (mestrado e doutorado) (UFV, 2015).

\section{Definição da amostra e técnicas de coletas de dados}

Foram selecionados de forma aleatória 13 docentes do magistério superior que estão lotados na UFV, campus Viçosa, sendo realizadas entrevistas semiestruturadas com questões relacionadas ao suporte familiar e outras referentes à carreira docente.

A definição para a escolha da quantidade de entrevistas a serem realizadas foi a saturação dos dados. O fechamento amostral por saturação teórica é definido como a suspensão de inclusão de novos participantes quando os dados obtidos passam a apresentar, na avaliação do pesquisador, uma certa redundância ou repetição, não sendo considerado relevante persistir na coleta de dados (FONTANELLA et al., 2008).

A coleta de dados se iniciou com a apresentação e explicação sobre a pesquisa, para a aplicação do Termo de Consentimento Livre e Esclarecido, a todos os sujeitos participantes da pesquisa, para então dar seguimento à realização das entrevistas semiestruturadas com os docentes.

\section{Análise e interpretação dos dados}

Para apresentação dos dados das 13 entrevistas com os docentes do magistério superior lotados na UFV, campus Viçosa, utilizou-se de letras e números (D1, D2, D3 ... D13) para preservar suas identidades. Assim, deu-se início à análise do conteúdo das falas transcritas e organizadas, segundo a vertente teórica de Olson et al. (2003), que conceitua o suporte familiar a partir de 3 fatores principais: diálogo, afetividade e conforto emocional, sendo analisado como uma categoria de análise; emergiram, a partir das falas dos 
docentes, 3 categorias de análise relacionadas à carreira docente e ao estresse ocupacional, dessa forma, totalizando 4 categorias de análise para esse estudo:

1. Percepção sobre a relação trabalho e família;

2. A carreira docente e suas interferências na relação familiar;

3. A vivência do suporte familiar dos docentes universitários;

a. Diálogos familiares sobre medos, preocupações e angústias;

b. Família, afetividade e conforto emocional;

4. Família e estresse ocupacional.

Segundo Bardin (2002), a análise de conteúdo é uma técnica de identificação de temas relevantes para explicar o objeto estudado, que resguarda características da mensagem propriamente dita do seu valor informacional, das palavras, argumentos e ideias nela expressos (LAVILLE; DIONNE, 1999).

Após a estruturação das categorias de análise, iniciaram-se as interpretações dos significados captados e intuídos nas mensagens analisadas, em sequência sendo realizada a interpretação das falas, pois a uma adequada análise de conteúdo não basta categorizar e descrever, mas também interpretar o conteúdo, conforme Miles e Huberman (1994). As variáveis empíricas que emergem dos dados do texto, que são conceituadas de modo indutivo quando cruzadas com as variáveis previamente construídas, acabam trazendo à entrevista e à análise do seu conteúdo maior clareza e sentido aos pressupostos estudados.

Ao final, buscou-se interpretar e discutir os resultados, apoiados pela literatura, se preocupando em responder as perguntas de pesquisa e cumprir os objetivos deste estudo. Além dos aspectos mencionados, buscou-se ampliar o conhecimento e as discussões sobre a problematização proposta.

Em todo o processo da pesquisa foram atendidos os princípios éticos dispostos na Resolução № 466/2012 do Conselho Nacional de Saúde, tendo este trabalho sido autorizado pelo Comitê de Ética em Pesquisa com seres humanos, da Universidade Federal de Viçosa, através do CAAE: 45243915.1.0000.5153 e parecer de número 1.116.358.

\section{Resultados e Discussão}

\section{Categoria 1 - Percepção sobre a relação trabalho e família}

Nesta categoria foi possível verificar o que representa a relação trabalho e família para os entrevistados, apresentando significados semelhantes entre os participantes da pesquisa. A partir das falas pode-se evidenciar que os docentes consideram a relação entre o trabalho e a família de extrema importância, sendo colocada como "fundamental". Expressam a necessidade do equilíbrio entre a vida familiar e a atividade ocupacional, sem sobreposição de valores e dedicação entre eles; notou-se, ainda, a presença do vínculo emocional e a valorização da família. Relataram, também, como as relações familiares podem influenciar o trabalho:

A relação entre a familia e o trabalho é fundamental (D1).

São duas coisas importantes para mim. A Família sempre foi na minha vida, embora eu tenha alguns momentos em que trabalho dez horas direto (D5).

Eu acho que são duas coisas que têm que se complementar [...] não pode se sobressair uma em relação à outra (D6).

Então, se tem algum problema na família [...] vai refletir no trabalho (D1).

Sem família não se faz nada (D1).

Prioridade absoluta (D5). 
O sentimento expresso pelos docentes com relação à família corrobora Souza e Baptista (2008), pois no referido trabalho os autores mencionam que a família é entendida como rede primária de interação social e provedora de apoio indispensável à manutenção da integridade física e psicológica do indivíduo.

Verifica-se, ainda, a importância da atividade ocupacional e a dedicação a mesma. Segundo Martinez (2002), o trabalho é um dos elementos da felicidade humana e a felicidade no trabalho é resultado da satisfação plena de necessidades psicossociais, do sentimento de prazer e do sentido de contribuição no exercício da atividade profissional. Porém, de acordo com Cecílio (2016), com as mudanças na sociedade onde as mulheres buscam cada vez mais o seu espaço no mercado de trabalho, passa a existir a necessidade de transformações nos papéis dentro da família, onde apenas a mulher era a cuidadora, agora o homem também passa a se responsabilizar aos cuidados do lar e a dividir as tarefas da casa. Surge, a partir dessas mudanças sociais, a necessidade de os trabalhadores tentarem equilibrar a vida pessoal com a profissional (ANDRADE, 2010).

\section{Categoria 2 - A carreira docente e suas interferências na relação e no tempo com família}

Os participantes desse estudo acreditam que o tempo dedicado à carreira como professor universitário pode acarretar interferências negativas às relações familiares. A ocorrência da necessidade de realizar viagens, segundo os docentes, é uma das situações que afeta a família; muitos docentes necessitam realizá-las para cumprir compromissos como congressos, palestras e cursos. Essa atividade diminui o tempo com a família devido à distância, além de causar cansaço.

Além da ausência ocasionada pelas viagens, o excesso de trabalho, a busca pela produtividade, a vaidade e até mesmo o perfeccionismo que a carreira exige geram uma sobrecarga aos docentes do magistério superior. De acordo com os relatos, essa sobrecarga prejudica as relações familiares, pois diminui os momentos de lazer, as atividades com os filhos, os momentos de diálogos e as atividades sociais, afetando, assim, o convívio familiar. Os docentes expressaram que seus familiares referem a dificuldade de compreender as ausências dos sujeitos no convívio familiar e nos momentos de lazer.

Viajo muito. E lógico, se você viaja muito é menos tempo com a família (D1).

[...] são as viagens, me ausentar, é difícil sair, é difícil de chegar, por causa das distâncias muitas vezes que a gente tem que correr (D2).

A família, ela paga o pato do excesso do trabalho. [...] ocupando espaços que você deveria se dedicar à sua família com um pouco mais de afinco e dedicação (D3).

[...] devido ao volume de trabalho [...] a produtividade e o tempo dedicado para pesquisa e para outras atividades acadêmicas que você acaba de fato tendo que dificilmente conciliar as duas coisas, ter tempo. [...] por conta da vaidade também que possuem, que exige o próprio mundo acadêmico, acaba afetando, com certeza, a relação familiar (D4). [...] nessa busca por sobrevivência, vencer as etapas, faz com que você quase busque a perfeição. E no transcorrer, principalmente, desses últimos anos, veio o doutorado e tudo isso $[\ldots](D 5)$.

[...] a gente acaba tendo que levar as coisas para fazer em casa. Então, muitas vezes, no final de semana eu estou fazendo alguma coisa do trabalho (D6).

Então, eu duvido muito que os professores da universidade consigam, de fato, em algum momento, fazer um dever com o filho, acompanhar os filhos na escola. Eu acredito que seja uma relação muito difícil de se acompanhar (D3).

[...] aí você começa a perder a sua vida social familiar (D8).

[...] Durante o dia é muito fácil administrar essa ausência em casa, porque elas (filhas) também tinham as atividades delas. À noite, elas esperavam pela presença da mãe. $E$ depois de passar um dia inteiro no trabalho, eu também tinha que dar aula à noite (D5). Então, a familia questionava "pô, você está trabalhando muito. [...] há um certo incômodo familiar em relação ao meu ritmo de trabalho (D1). 
Então, no passado eu estava te contando que o meu pai sempre me cobrava [...] a minha presença (D5).

[...] e o meu marido se incomoda um pouco com essa situação de eu ter que ficar tirando o meu tempo de final de semana para poder estudar. [...] primeiro foi mestrado, o que você vai inventar agora? (D6)

Conforme análises realizadas por Gomes (2014) e Brasileiro (2013), o lazer deve ser considerado uma necessidade humana que se compõe na junção de três elementos: a ludicidade, as manifestações culturais e o tempo/espaço social. Essa necessidade pode ser realizada de diversas formas, segundo os valores e interesses dos sujeitos, grupos e instituições

Desse modo, o trabalho, o lazer e a família estabelecem relações que os interligam (PINTO, 2008). Segundo Blass (2004 citando ELIAS e DUNNING, 1992), é necessário, repensar as conexões previamente estabelecidas entre tempo livre e lazer, que é "todo tempo liberto das ocupações de trabalho". Dessa forma, nos momentos de lazer, a relação das pessoas com o tempo se daria de forma desinteressada e dispersa - o que, na maioria das vezes, não acontece, como ocorre com os docentes da UFV.

As vivências estabelecidas no lazer ultrapassam o espaço-lugar, pois vão além do espaço físico por ser um momento do qual os sujeitos se apropriam no sentido de transformá-lo em ponto de encontro (consigo, com o outro, e com o mundo) e de convívio social. Assim, os sujeitos ampliam relações de sociabilidade. Os momentos de lazer com a família significam compartilhar vivências, estreitar laços, bem como compensar ausências estabelecidas nos familiares devido à rotina de trabalho dos docentes (GOMES, 2004).

Além das questões já mencionadas, observou-se um outro fator que afeta a vida dos docentes ao se sobrecarregarem com o trabalho e terem uma diminuição do tempo com a família. Essa situação traria consigo a vivência do sentimento de culpa. No momento da entrevista, foram observadas, além das falas, alterações no tom de voz, lágrimas nos olhos, representando sentimento de tristeza e angústia, pela sensação de impotência diante da situação, como se pode verificar nos relatos a seguir:

Eu me sinto "estou abandonando os meninos (filhos), deixando-os" (D3).

[...] você acha tendo que deixar de dar tanta atenção à família para se dedicar ao trabalho.

[...] No meu caso eu moro com o meu pai, meu pai, eu vim para cá mais por conta dele

[...] ele teve um infarto, depois teve outros problemas cardíacos, agora teve um AVC ano passado, então ele tem uma limitação física. E ele fica muito dentro de casa e gosta de sair sempre, só que devido a minha correria, eu também não tenho tempo de dar tanta atenção e levar onde ele quer, então, ele sempre reclama, "ah, tem carro em casa, tem motorista, mas não posso sair" (D4).

O conflito entre o trabalho e a família não se explica pela mensuração de volume ou dedicação objetiva de trabalho, mas de uma medida subjetiva da relação trabalho versus família, sob a visão do trabalhador, como ou quanto o trabalho rouba do tempo que o trabalhador, nesse caso, os docentes poderiam estar se dedicando à família. Pois, nessa percepção, a família foi prejudicada do seu convívio em função do trabalho (ASHFORTH, 1996; CARVALHO, 2016).

Portanto, a relação trabalho versus família é uma relação biunívoca onde o trabalho afeta a família e a família afeta o trabalho (BURKE, 1994; CARLOTTO, 2014). O conflito vivido de forma contínua, com a sensação de que o trabalho estaria roubando um tempo vital de dedicação à família, leva ao sofrimento psíquico e à exaustão emocional (CODO, 1997; CECÍLIO, 2016).

\section{Categoria 3 - A vivência do suporte familiar dos docentes universitários}

A família é responsável pelo suporte social e familiar ao indivíduo, além de prover alimentação, abrigo, educação e outras necessidades materiais, como descrito no Código Civil Brasileiro. É também responsabilidade da dinâmica familiar proporcionar apoio e proteção, promover laços afetivos e favorecer 
a construção da identidade pessoal de seus membros (SZYMANSKI, 2002). É no contexto familiar que cada indivíduo aprende as questões iniciais e primordiais para a futura convivência em sociedade, como amor, carinho, respeito, moral, ética e sociabilidade (BAPTISTA; DIAS, 2004; BAPTISTA; OLIVEIRA, 2010). Dessa forma, com base na vertente teórica de Olson et al. (1983), que conceitua o suporte familiar a partir de três esferas principais - diálogo, afetividade e conforto emocional -, pode-se averiguar que a família é vista pelos docentes como aquela que mantém todas as bases para o equilíbrio emocional através do diálogo, afeto, compreensão e apoio.

\section{a. Diálogo familiar sobre medos, preocupações e angústias}

Os docentes consideram importante a comunicação da família através dos diálogos sobre os acontecimentos diários e vivências ocupacionais, como forma de expor suas fragilidades, medos, angústias e preocupações. Dessa forma, criam-se laços de afeto e suporte sociais mais estruturados, proporcionando o sentimento de acolhimento, compreensão e apoio.

O apoio recebido da família relatado pelos docentes é denominado de suporte familiar, conforme mostram as teorias Olson (1983) e Seidl (2006), que apoiam-se em uma questão importante não somente para o desenvolvimento global do indivíduo, mas também para a qualidade do relacionamento estabelecido entre os membros da família, estando relacionado aos fatores psicológicos, como expressão de carinho, atenção, comunicação, proximidade afetiva, permissão de autonomia, liberdade e independência, proteção e diálogo (BAPTISTA; DIAS, 2010; SOUZA, 2008; BAPTISTA; OLIVEIRA, 2004; GREENBERGHER, 2000).

Ah, sim claro. Isso é normal, as conversas em família (D1).

Sim. Muito. Eu sou um pouco privilegiado, porque minha esposa é docente federal também. A gente conversa muito sobre as questões dos respectivos departamentos, os problemas que ela vive lá e que eu vivo aqui. A gente tem uma relação de diálogo muito forte nesse sentido, sim (D3).

[...] eu busco passar para elas as minhas dificuldades e as minhas fragilidades. E dizer que "olha, é o esforço que nos leva, nos faz caminhar". [...] hoje elas me ligam para falar das fragilidades, medos e angústias: "Ai, mãe, estou com isso aqui no trabalho, eu estou com essa e aquela dificuldade. ah! Me confidenciam os desafios, as fragilidades delas (filhas) (D5).

Sempre, todos os dias. [...] Porque eu acho que pelo menos eu sinto que quando eu converso, eu me sinto acolhida (D6).

[...] você tem que conversar todo dia é essencial, [...] acho que isso é importante (D2).

No suporte familiar, relatado pelos docentes, verifica-se um delineado pela coesão, adaptabilidade e comunicação, corroborando os estudos de Batista (2010) e Olson (2003). A coesão refere-se ao vínculo entre os membros familiares e a possibilidade de se tornarem, com o tempo, indivíduos autônomos. A adaptabilidade diz respeito à capacidade de ajuste familiar a possíveis mudanças que possam acarretar em transformações na estrutura e dinâmica familiar, como percebe-se na vivência dos docentes por mudanças de cidades, viagens e doenças, enquanto a comunicação se refere à forma como conseguem expressar as ideias e sentimentos e à capacidade dos membros familiares de se entenderem (BAPTISTA, 2004; OLSON, 2003).

\section{b. Familia, afetividade e conforto emocional}

Os docentes do magistério superior demonstraram em seus depoimentos que a sua rede de apoio se encontra na própria família que a preserva, de várias formas, sendo sua unidade considerada um 
alicerce. Foram nítidas as manifestações de carinho, afeto e compreensão entre os membros da família que justificaram esta afirmação; são fontes de apoio emocional porque disponibilizam tempo, compartilham as vivências cotidianas, preocupações e emoções, oferecem carinho e afeto. Os momentos em família trazem consigo a sensação de tranquilidade, de prazer e bem-estar, reestabelecendo o equilíbrio pessoal o que contribui para a realização das atividades profissionais.

\author{
A Familia é que me sustenta bem (D1). \\ Eu tenho uma relação com a família que me dá um conforto, assim, enorme. Eu acho que \\ é onde eu fico, consigo ficar tranquilo e me recompor para poder voltar ao trabalho (D3). \\ Proporciona, sim (D4). \\ [...] ter uma consciência do quanto a família importa para me dar as bases para que eu \\ fique bem aqui (no trabalho) [...] não, mãe, você dá conta. Você lembra que isso aconteceu \\ no passado?" - me resgata, sabe? É muito legal (D5). \\ [...] acho que a casa, a família, tem que ser o suporte. E esse suporte, para mim, é muito \\ importante. [...] você quer sentir que a pessoa se importa com aquilo que você está \\ passando. E eu sinto isso com a minha família (D6). \\ Sim. Bastante. Eu tenho na família uma atividade prazerosa, que dá um certo... ajuda a \\ restabelecer o equilibrio pessoal. Eu penso assim (D8). \\ A família eu vejo como o nosso maior pilar (D5).
}

O papel da família dos docentes do magistério superior da UFV se baseia em um modelo psicossocial, que distingue o sistema familiar com a definição de papéis - cada membro ocupa o seu espaço que não é permutável. Todavia, a expectativa de que cada papel possa sofrer alteração, permitindo a transição entre "o proteger" e "ser protegido" (KIM-GODWIN, 2004; PUSCHEL, 2006). Isso garante uma dinâmica nas trocas de papéis que proporciona a saúde familiar frente as diversas adversidades encontradas nas relações e a vida. As relações entre os membros da família se amparam em uma complexa rede de interação constante, que se apoia em círculos de afeto e que objetivam a sustentação em relação ao todo. Assim, pode-se considerar os docentes como indivíduos, seres multidimensionais, com uma história singular, construída em um contexto familiar que também é único (PUSCHEL, 2006; MOMBELLI, 2011).

Dessa forma, de acordo com o tipo de percepção que o indivíduo tem de sua família, as influências externas e a interação pessoa-família podem agir de forma positiva ou negativa à saúde familiar, como fatores protetivos ou de risco no surgimento de distúrbios mentais e problemas emocionais (BAPTISTA, 2004; DELL'AGLIO, 2004; MOTA, 1999). Sendo observadas nos docentes as influências da família de forma positiva, ou seja, protetiva, que compõem e melhoram a saúde e a qualidade de vida familiar.

\title{
Categoria 4 - Familia e estresse ocupacional
}

A Organização Internacional do Trabalho reconheceu que, no século XXI, o trabalho está se transformando em um fator decisivo e gerador de quadros neuróticos e desestabilizadores da saúde mental. Entre os quadros mais comuns de adoecimentos incapacitantes relacionados ao trabalho, devido ao estresse e à sobrecarga, destacam-se os transtornos de adaptação, associados a quadros de ansiedade, estresse crônico e fadiga patológica, além dos transtornos de angústia e depressivos (OIT, 2001; STANSFELD, 2006; ANDRADE, 2010; CECÍLIO, 2016).

No entanto, o que poderia amenizar os quadros neuróticos que desestabilizam a saúde mental no trabalho é o suporte familiar, agindo como um apoio emocional para que os trabalhadores possam ter um enfrentamento adequado aos desafios apresentados no universo ocupacional.

No estudo com os docentes do magistério superior da UFV, pode-se observar o sentimento de pertencimento à família, também sentimentos de afeto, amor e segurança, todos esses, se expostos e vividos, contribuem como forma de proteção ao estresse, diminuindo seus efeitos negativos e promovendo 
a saúde mental, além de aumentar as condições de resiliência e bem-estar psicológicos (RAMOS, 2002; KILIMNIK, 2015).

Sim, se tiver uma relação familiar tranquila. Equilibrar. [...] Atenua demais (D1).

[...] A família atenua muito o estresse [...] Muito (D3).

Sim, acho que tranquilamente. Acho que quanto maior o nivel de diálogo, com a família, melhor para lidar com essa situação de estresse. [...] diminui pela compreensão, pela tranquilidade que proporciona [...] a família é um suporte em relação a isso (estresse), pelos programas, pela convivência, pelo entendimento também da situação, de situações diversas (D4).

Com toda a certeza. [...] Eu acho que quando você vai para casa é aquele ambiente de acolhimento. Então, se você encontra esse conforto do estar em casa, sentir-se em seu lugar, é difícil até manter esse conforto em qualquer outra parte. Então, eu... para mim, familia é a base para tudo (D5).

[...] acho que a família é essencial. Sem a família, eu acho que a gente deve ser mais estressada. Dependendo da família. [...] Eu acho que atenua. Mas, em alguns momentos, aumenta. Mas eu acho que mais atenua do que aumenta (D6).

[...] Eu creio que diminui o estresse. Se [...] tiver uma família - vamos dizer assim - que proporciona um conforto, um prazer de estar com a família, eu acho que isso ajuda bastante. No meu caso, por exemplo, eu tenho uma família, feliz, esposa, filhos pequenos e tal, eu vivo uma fase familiar muito boa, então, eu sinto que isso é [...] às vezes, um ponto de equilíbrio, de descanso, de prazer, prazer pessoal. Não que não afeta, às vezes, a profissão, mas eu digo assim, [...] no caso, de certa forma, equilibrar o nível de estresse, colocando assim, quando você tem atividade de lazer, de tempo dedicado à família, eu acho que isso de uma certa maneira é um porto seguro para dar um equilibrio (D8).

Porém, em algumas verbalizações foi possível compreender que o trabalho influencia na convivência familiar de forma negativa. Principalmente, quando os docentes necessitam se ausentar dos momentos de lazer em família, devido à sobrecarga de trabalho. A situação pode causar um sofrimento psíquico ao docente e um sentimento de abandono à família, que se sentirá pressionado pela cobrança por sua presença pelos seus familiares, com isso, reduzindo e negativando o suporte familiar.

A ocorrência de variação na percepção do suporte familiar pode ser explicada pelas demandas que se apresentam a cada momento da vida. A família pode ser mais ou menos apoiadora. Tal aspecto pode ser um obstáculo que surge no transcorrer do seu ciclo vital (CARTER, 1989). Em cada momento da vida, o suporte familiar se apresentará de formas diversas, expondo seu aspecto dinâmico e se reestruturando a cada dificuldade e nova etapa no curso de vida do indivíduo.

\section{Considerações finais}

Através da realização do estudo, pode-se compreender a percepção dos docentes do magistério superior da UFV, lotados no campus Viçosa, sobre o suporte familiar, a relação entre o suporte familiar vivenciado e a carreira docente e suas interferências no estresse ocupacional.

A relação entre trabalho e família, para os docentes, apresentou significados semelhantes e evidenciou a existência de uma relação de extrema importância, sendo colocada muitas vezes como "fundamental". Expressaram a necessidade do equilíbrio entre a vida familiar e a atividade ocupacional, sem sobreposição de valores e dedicação entre eles.

Os participantes do estudo relataram que o tempo dedicado à carreira como professor universitário pode acarretar interferências negativas nas relações familiares. Sendo o excesso de trabalho, as viagens, a busca pela produtividade, a vaidade e o perfeccionismo os principais fatores responsáveis 
para caracterizar a sobrecarga de trabalho. Essa sobrecarga prejudica as relações familiares, pois diminui os momentos de lazer e o convívio familiar. A diminuição do convívio familiar implica um prejuízo, por exemplo, na atividade com os filhos, momentos de diálogo, atividades sociais em família, o que, por consequência, afeta a dinâmica familiar. Foi observado que essa situação traz consigo a vivência do sentimento de culpa, de tristeza e angústia, pela sensação de impotência diante da situação.

Os docentes consideram importante a comunicação da família através dos diálogos sobre os acontecimentos diários e vivências ocupacionais, como forma de expor suas fragilidades, medos, angústias e preocupações. Dessa forma, criam-se laços de afeto e um suporte social estruturado, proporcionando o sentimento de acolhimento, compreensão e apoio. Esse apoio recebido da família relatado pelos docentes pode ser considerado como suporte familiar. No suporte familiar relatado verifica-se que o mesmo é delineado pela coesão, adaptabilidade e comunicação.

Observou-se, ainda, que os docentes universitários encontram sua rede de apoio na própria família que também a preserva. Os momentos em família trazem consigo a sensação de tranquilidade, de prazer e bem-estar, reestabelecendo o equilíbrio pessoal o que contribui para a realização das atividades profissionais. Os sentimentos mencionados, expostos e vividos, contribuem como forma de proteção ao estresse ocupacional, diminuindo seus efeitos negativos e promovendo a saúde mental, além de aumentar as condições de resiliência e bem-estar psicológico nos docentes.

Em contrapartida, o trabalho influencia em alguns momentos a convivência familiar de forma negativa, quando os docentes necessitam se ausentar dos momentos de lazer em família devido à sobrecarga de trabalho. Essa situação causa um sofrimento psíquico ao mesmo e um sentimento de abandono à família, reduzindo a efetividade do suporte familiar.

Dessa forma, conclui-se que os docentes do magistério superior da UFV apresentam o sentimento de apoio e suporte familiar, bem como promovem esse suporte aos membros de sua família. $\mathrm{O}$ suporte familiar é capaz de diminuir o estresse ocupacional e auxilia na manutenção do equilíbrio emocional dos mesmos. Com isso, observa-se a necessidade de uma dedicação maior e ampliação do tempo familiar e a diminuição da sobrecarga no trabalho docente. Nota-se a importância do desenvolvimento de políticas públicas, bem como de práticas e ações, tanto em instituições públicas quanto privadas, que visem às condições, manutenção e estímulo às vivencias familiares. Considerando a família como parte fundamental à sustentação da saúde mental dos trabalhadores, suas relações devem ser incentivadas. E quando o suporte familiar estiver ausente, deve-se estimular sua estruturação através de ações, como, por exemplo, terapia familiar pelas instituições, contribuindo para preservar a saúde do trabalhador, que, no caso do estudo, são os professores do magistério superior de uma instituição federal de ensino.

\section{Referências}

ANDOLFI, M. et al. O indivíduo e a família: dois sistemas em evolução. In: ANDOLFI, M. et al. (Orgs.) Por trás da máscara familiar: um novo enfoque em terapia da família. Porto Alegre: Artes Médicas, 1994. p. 17-39.

ANDRADE, C. Trabalho e família na transição para a idade adulta. Porto: Livpsic, 2010.

ASHFORTH, B.E.; LEE, R.T. A meta-analytic examination of the correlates of the three dimensions of Job Burnout. Journal of Applied Psychology, v. 81, n. 2, p. 123-133, 1996. https://doi.org/10.1037/0021-9010.81.2.123.

BAPTISTA, M.N., NORONHA, A.P.P., CARDOSO, H.F. Relações entre suporte familiar e interesses profissionais. Revista Salud \& Sociedad, v. 1, n. 1, p. 28-40, 2010.

BAPTISTA, M.N.; OLIVEIRA, A.A. Sintomatologia de depressão e suporte familiar em adolescentes: um estudo de correlação. Revista Brasileira de Crescimento e Desenvolvimento Humano, v. 14, n. 3, p. 58-67, 2004. https://doi.org/10.7322/jhgd.40168.

BARDIN, L. Análise de conteúdo. Lisboa: Edições 70, 2002.

BETORET, F.D.; ARTIGA, A.G. Barriers perceived by teachers at work, coping strategies, self-efficacy and burnout. The Spanish Journal of Psychology, v. 13, n. 2, p. 637-654, 2010. https://doi.org/10.1017/S1138741600002316.

BLASS, L.M.S. Nas interfaces do trabalho, emprego e lazer. Caderno CRH, Salvador, v. 17, n. 41, maio/ago. 2004.

BRASILEIRO, M.D.S. O lazer e as transformações socioculturais contemporâneas. Revista Lusófona de Estudos Culturais, v. 1, n. 2, 2013. 
BURKE, R.J. Stressful events, work-family conflicty, coping, psychological Burnout, and well-being among police officers. Psychological Reports Relations, v.75, n.2, 1994.

CAMPOS, E.P. Suporte social e família. In: MELLO FILHO, J. (Org.) Doença e família. São Paulo: Casa do Psicólogo, 2004. p. $141-161$. CARLOTTO, M.S.; CÂMARA, S.G. Tradução, adaptação e exploração de propriedades psicométricas da Escala Interação TrabalhoFamília Nijmen(SWING) em uma amostra de professores brasileiros. Estudos de Psicologia, v.19, n.3, 2014.

CARVALHO, V.S.G. A relação trabalho-família: o desafio para ontem. Tese (Doutorado em Psicologia) - Faculdade de Psicologia, Universidade de Lisboa, 2016.

CARTER, B., MCGOLDRICK, M. As mudanças no ciclo de vida familiar: uma estrutura para a terapia familiar. 2. ed. Porto Alegre: Artmed,1995.

CASTANHO, S.; CASTANHO, M.E.L.M. (Orgs.). O que há de novo na educação superior: do projeto pedagógico à prática transformadora. 2. ed. Campinas: Papirus, 2004.

CEBERIO, M. R. Viejas y nuevas familias. La transición hacia nuevas estructuras familiares, 2006.

CECÍLIO, P. L. M. Influência do conflito trabalho-família na atitude e nas emoções dos professores. Dissertação (Mestrado em Gestão) - Escola Superior de Tecnologia e Gestão, Instituto Politécnico de Leiria.

CODO, W. Um diagnóstico do trabalho (em busca do prazer). In: TAMAYO, A.; CODO, W.; BORGES, J.E. (Orgs.). Trabalho, organizações e cultura. Cooperativa de Autores Associados, 1999.

CONTAIFER, Tatiana Rodrigues Corrêa et al. Estresse em professores universitários da área de saúde. Revista Gaúcha de Enfermagem, v. 24, n. 2, p. 215, 2003.

DARIDO, S. C. Apresentação e análise das principais abordagens da educação física escolar. Revista Brasileira de Ciência do Esporte, 1998.

DELL'AGLIO, D. D.; HUTZ, C. S. Depressão e desempenho escolar em adolescentes institucionalizados. Psicologia: Reflexão e Crítica, v.17, n. 3, p. 341-350, 2004. https://doi.org/10.1590/S0102-79722004000300008.

ELIAS, N.; DUNNING, E. A busca da excitação. Lisboa: Difel, 1992.

FERNANDES, C.M.B. Formação do professor universitário: tarefa de quem? In: MASETTO, M. Docência na universidade. Campinas: Papirus, 1998.

FONTANELLA, B. J. B.; RICAS, J.; TURATO, E. R. Amostragem por saturação em pesquisas qualitativas em saúde: contribuições teóricas [Saturation sampling in qualitative health research: theoretical contributions]. Cad Saúde Pública, v. 24, n. 1, p. 17-27, 2008. https://doi.org/10.1590/S0102-311X2008000100003.

GOMES, C.L. Verbete lazer - Concepções. In: GOMES, C.L. (Org.). Dicionário crítico do lazer. Belo Horizonte: Autêntica, 2004.

GOMES, C. L. Lazer: necessidade humana e dimensão da cultura. Revista Brasileira de Estudos do Lazer, v. 1, n.1, p.3-20, 2014.

GREENBERGHER, E.; CHEN, C., TALLY, S.R.; DONG, Q. Family peer and individual correlates of depressive symptomatology among US and Chinese adolescents. Journal of Consulting and Clinical Psychology, v. 68, p. 209-219, 2000. https://doi.org/10.1037/0022006X.68.2.209.

IANNI, O. O professor como intelectual: cultura e dependência. In: CATTANI, D.B et al. (Orgs.). Universidade, escola e formação de professores. São Paulo: Brasiliense, 1986. p. 39-49.

KERR, R.A. et al. A qualitative study of workplace stress and coping in secondary teachers in Ireland. Irish Journal of Applied Social Studies, v. 11, n. 1, 2011.

KILIMNIK, Z.M. et al. O significado do trabalho: um estudo com professores de administração em uma universidade. Revista Lugares de Educação, v. 5, n. 11, 2015.

KIM-GODWIN Y. S. Family roles. In: BOMAR, P.J. Promoting health in families: applying family research and theory to nursing practice Philadelphia (PA/USA): Saunders, 2004. p.117-39.

KOKKINOS, C. M. Job stressors, personality and Burnout in primary school teachers. British Journal of Educational Psychology, v. 77, n. 1, p. 229-243, 2007. https://doi.org/10.1348/000709905X90344.

LAVILLE, Christian; DIONNE, Jean. A construção do saber: manual de metodologia da pesquisa em ciências humanas. UFMG: Artmed, 1999.

LIPP, M.N.; MALAGRIS, L.N. O stress emocional e seu tratamento. In: RANGE, Bernard (Org.). Terapias cognitivo-comportamentais: um diálogo com a psiquiatria. São Paulo: Artes Médicas, 2001, p. 475-489.

LIPP, M.N. Stress e o turbilhão da raiva. São Paulo: Casa do Psicólogo, 2005.

MARTINEZ, M. C. As relações entre a satisfação com aspectos psicossociais no trabalho e a saúde do trabalhador. Dissertação (Mestrado em Psicologia), Universidade de São Paulo, São Paulo, 2002.

MILES, M.B.; HUBERMAN, A.M. Qualitative data analysis: an expanded sourcebook. $2^{\text {nd }}$ ed. London: Sage, 1994.

MOMBELLI, M.A. et al. Estrutura e suporte familiar como fatores de risco de stress infantil. Estudos de Psicologia, Campinas, v. 28, n. 3, p. 327-335, jul./set. 2011. https://doi.org/10.1590/S0103-166X2011000300004. 
MONTGOMERY, C., RUPP, A.A. A meta-analysis for exploring the diverse causes and effects of stress in teachers. Canadian Journal of Education, v. 28, n. 3, p. 461-488, 2005. https://doi.org/10.2307/4126479.

MOTA, E. L.A.; FRANCO, A.L.S.; MOTTA, M.C. Migração, estresse e fatores psicossociais na determinação da saúde da criança. Psicologia, Reflexão e Crítica, v. 12, n. 1, p. 119-132, 1999. https://doi.org/10.1590/S0102-79721999000100008.

OLIVEIRA, M.A.T. de. A Revista Brasileira de Educação Física e Desportos (1968- 1984) e a experiência cotidiana de professores da Rede Municipal de Ensino Curitiba: entre a adesão e a resistência.398f. Tese (Doutorado em História e Filosofia da Educação) - Pontifícia Universidade católica de São Paulo, São Paulo, 2001.

OLSON, D.H.; GORALL, D.M. Circumplex model of marital and family systems. In: WALSH, F. Normal Family Processes. $3^{\text {rd }}$ ed. [Online]. New York: Guilford, 2003. p. 514-547. https://doi.org/10.4324/9780203428436 chapter 19.

OLSON, D.H.; RUSSELL, C.S.; SPRENKLE, D.H. Circumplex model of marital and family systems: vi. Theoretical update. Family Process, Malden/USA, v. 22, p. 69-83, 1983.

ORGANIZACIÓN INTERNACIONAL DEL TRABAJO, 2001. Disponível em: http://www.ilo.org/global/publications/lang--es/index.htm. Acesso em: 3 out. 2011

PEREIRA, O.A.V. Qualidade de vida no trabalho de docentes universitários de uma instituição pública e outra privada do leste de Minas Gerais. Centro Universitário de Caratinga-MG, 2006.

PÉREZ, J.R. Stress no ambiente organizacional: conceitos e tendências. Boletim de Psicologia, São Paulo, v. 42, n. 96/97, p. 89-97, jan./dez. 1992.

PINTO, S. G. Relações entre família, trabalho e lazer: o caso dos professores da Universidade Federal de Viçosa. (Dissertação em Economia Doméstica) - Universidade Federal de Viçosa, 2008.

PUSCHEL, V.A.A.; IDE, C.A.C.; CHAVES, E.C. Modelos clínicos e psicossocial de atenção ao indivíduo e à família na assistência domiciliar: bases conceituais. Rev. Esc. Enferm. USP, v. 40, n. 2, p. 261-8, jun. 2006. https://doi.org/10.1590/S0080$\underline{62342006000200015}$.

RAMOS, M.Z.; TITTONI, J.; NARDI, H.C. A experiência de afastamento do trabalho por adoecimento vivenciada como processo de ruptura ou continuidade nos modos de viver. Cadernos de Psicologia Social e do Trabalho, v. 11, n. 2, p. 209-221, 2008. https://doi.org/10.11606/issn.1981-0490.v11i2p209-221.

SILVA, R. da. Características do estilo de vida e da qualidade de vida de professores do ensino superior público em educação física. 265f. Tese (Doutorado em Engenharia de Produção) - Centro Tecnológico, Universidade Federal de Santa Catarina, 2006.

SINGER, P.I. A formação da classe operária. São Paulo: Ed. da UNICAMP, 1986.

SOUZA, M.S.; BAPTISTA, M.N. Associações entre suporte familiar e saúde mental. Psicol. Argum, 2008.

STANSFELD, S.; CANDY, B. Psychosocial work environment and mental health - a meta-analytic review. Scandinavian Journal of Work and Environmental Health, v. 32, p.443-462, 2006. https://doi.org/10.5271/sjweh.1050.

SZYMANSKI, H. Teorias e "teorias" de família. In: CARVALHO, M.C.B. (Org.). A família contemporânea em debate. 4. ed. São Paulo: Cortez, 2002.

TAFFAREL, C. N. Z. Currículo, formação profissional na educação física \& esporte e campos de trabalho em expansão: antagonismos e contradições da prática social. Movimento, Porto Alegre, v. 4, n. 7, p. 43-51, 1997.

UNIVERSIDADE FEDERAL DE VIÇOSA. UFV em números 2014. Disponível em: www.ufv.br/ppo. Acesso em: 16 mar. 2015.

VASQUES-MENEZES, I.; CODO, W.; MEDEIROS, L. O conflito entre o trabalho e a família e o sofrimento psíquico. Disponível em: http://psicologia139.dominiotemporario.com/doc/ Cap_14.pdf. Acesso em 03 de setembro de 2013.

YONG, Z.; YUE, Y. Causes for burnout among secondary and elementary school teachers and preventive strategies. Chinese Education and Society, v. 40, n. 5, p. 78-85, 2007. https://doi.org/10.2753/CED1061-1932400508. 